\title{
Targeted Epidural Blood Patches Under Fluoroscopic Guidance For Incidental Durotomies Related To Spine Surgeries: A Case Series
}

This article was published in the following Dove Press journal: Journal of Pain Research

\section{Andrew K Wong $(\mathbb{D}$ \\ Mohammad R Rasouli \\ Andrew Ng \\ Dajie Wang}

Department of Anesthesiology, Sidney Kimmel Medical College at Thomas Jefferson University Hospital, Philadelphia, PA, USA
Correspondence: Dajie Wang Department of Anesthesiology, Sidney Kimmel Medical College at Thomas Jefferson University Hospital, 3 Crescent Dr. Philadelphia PA, 19112 Philadelphia, PA, USA

Email Dajie.wang@jefferson.edu
Introduction: Incidental durotomies are usually managed conservatively. However, $1.8 \%$ of patients require surgical dural repair for CSF leak. There are limited data available regarding the use of epidural blood patches (EBP) for persistent CSF leaks secondary to incidental durotomies. This case series aims to evaluate the efficacy of targeted EBPs under fluoroscopic guidance in the treatment of incidental durotomies.

Methods: Four patients with incidental durotomies after spine surgeries (one cervical decompression, one revision of L5-S1 decompression and fusion, and two lumbar decompressions) were included in this series. These patients did not respond to conservative management and subsequently underwent EBPs. Magnetic resonance imaging (MRI) images were reviewed to confirm and identify the sites of CSF leak prior to the EBPs. We targeted the sites of CSF leak with fluoroscopic guidance. All four patients received an EBP with an 18-gauge epidural needle placed under fluoroscopic guidance. In some cases, epidural catheters were used to further target the sites of CSF leak. Contrast was used to confirm the appropriate placements of the needles and catheters. Approximately 5-14 mL of autologous blood was injected through the needles or catheters to the sites of dural leak.

Results: Three lumbar and two cervical EBPs were performed in four patients (two females and two males). Their age ranged from 44 to 73 years old. Two out of three patients who had lumbar EBP reported complete resolution of symptoms following EBP. The patient who had cervical epidural patches did not have improvement in her symptoms.

Conclusion: This case series demonstrated that targeted EBP can be an effective treatment for CSF leak from incidental durotomies. However, dural tears in the cervical region may be more difficult to treat. Larger scale studies are required to evaluate efficacy of EBP in the treatment of symptomatic incidental durotomies.

Keywords: durotomy, spine surgery, headache, epidural blood patch, CSF leak

\section{Introduction}

Incidental tear of the dural sac with subsequent cerebrospinal fluid (CSF) leak and lowpressure headache is one of the most common complications following spinal surgeries. In the literature, the reported incidence of this complication is up to $14 \%$. ${ }^{1}$ The highest frequency of incidental durotomy has been reported in patients undergoing revision spine surgeries. ${ }^{2,3}$ Dural tears with leakage of CSF can be recognized and repaired intraoperatively. Unrecognized leaks may present in a delayed fashion postoperatively or after discharge. Occult CSF leaks occur at a rate of $0.28 \%{ }^{4}$ CSF leaks are most commonly associated with positional headaches from intracranial hypotension, which can be managed conservatively with hydration, bed rest, and caffeine. 
Treatments for persistent CSF leaks that failed conservative management consist of surgical exploration and repair, and less invasive interventions including lumbar subarachnoid drain or epidural blood patch (EBP). ${ }^{1,5}$

The EBP is an effective treatment for postdural puncture headache related to spinal or epidural anesthesia, lumbar puncture for CSF analysis, and other spinal procedures. $^{5,6}$ In addition, there are case reports in the literature that EBP was also used in the treatment of postsurgical CSF leak or fistula. ${ }^{7-12}$ However, the efficacy and safety of this intervention for postsurgical CSF has not been well studied. In this case series, we described our experience of targeted EBP under fluoroscopy guidance for four patients with persistent dural leak following spine surgeries. Written informed consentwas obtained from the patients to have their case details published, and this case review was approved by institutional research board at Thomas Jefferson University. A summary of the study patients was presented in Table 1 .

\section{Case Descriptions}

\section{Patient I}

A 73-year-old female with a medical history of lumbar spinal stenosis who underwent left L4-5 laminectomy, medial facetectomy, and foraminotomy. She developed positional headache about four weeks after the surgery. She had tried conservative treatments including hydration, caffeine and an abdominal binder. Her physical examination was unremarkable. Her magnetic resonance imaging (MRI) of the lumbar spine revealed a large pseudomeningocele at L4-5 (Figure 1). Her neurosurgeon recommended a lumbar epidural blood patch. Given her persistent symptoms and failed

Table I Summary Of Study Patients

\begin{tabular}{|c|c|c|c|c|}
\hline & Patient I & Patient 2 & Patient 3 & Patient 4 \\
\hline Age (Years) & 73 & 48 & 44 & 55 \\
\hline Sex & Female & Male & Female & Male \\
\hline Body mass index $\left(\mathrm{kg} / \mathrm{m}^{2}\right)$ & 22.6 & 30.7 & 31.3 & 23.8 \\
\hline \multirow[t]{2}{*}{ Spine surgery } & L4-L5 & Revision L4-L5 Decompression/ & $\mathrm{C} 6-\mathrm{C} 7$ & L4-5 and L5-SI \\
\hline & Decompression & Fusion & Foraminotomy & laminectomy \\
\hline Pseundomeningocele & Yes & Yes & No & Yes \\
\hline EBP level & L4-5 & L5-SI & C6-7 & L4-5 \\
\hline Amount of blood infused & $12 \mathrm{~mL}$ & $10 \mathrm{~mL}$ & $4 \mathrm{~mL}$ & $14 \mathrm{~mL}$ \\
\hline Complications & None & None & None & None \\
\hline Respond to EBP & Yes & Yes & No & No \\
\hline Surgical dural repair & No & No & Yes & Yes \\
\hline Duration of follow-up & 6 months & 6 months & 3 months & I month \\
\hline
\end{tabular}

Abbreviation: EBP, epidural blood patch.

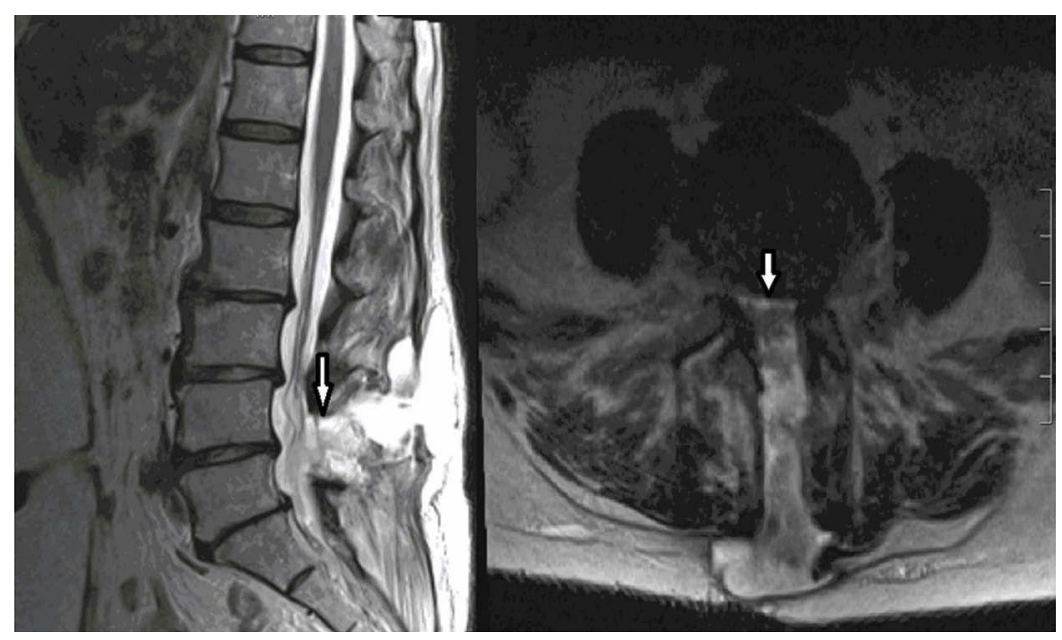

Figure I Lumbar spine MRI demonstrating epidural fluid collection and development of pseudomeningocele. CSF leak at right L4 laminectomy site marked by the arrows. Left: sagittal view, Right: axial view. 
conservative treatments, we agreed with the recommendation from neurosurgery and proceeded with an EBP. Prior to the EBP, we reviewed the MRIsand confirmed the presence of a large CSF leak at the left L4-5 laminectomy site (Figure 1). The prior laminectomy precluded us from using our traditional loss of resistance to access the epidural space at the left L4-5 interlaminar space. For this case, in order to place the blood patch close to the site of CSF leak at the left L4-5 laminectomy site, we used a left paramedian approach to access the L5-S1 interlaminar space, placed an epidural catheter through the needle and advanced this catheter to the site of CSF leak at L4-5 level. The brief description of this procedure is as follow: Lumbar EBP was performed in the prone position using a left paramedian approach under fluoroscopic guidance. The epidural space was accessed at L5-S1 interlaminar space (Figure 2). An epidural catheter was placed into the needle and advanced to L4-5 level of the spine. Contrast was injected and visualized in the epidural space at the L4-5 level, which was the site of CSF leak. Approximately $12 \mathrm{~mL}$ of autologous blood was injected through the needle. The patient had immediate improvement of her headache after the EBP. Her headache completely resolved three days after the procedure. At a six-month follow-up, this patient remained headache free.

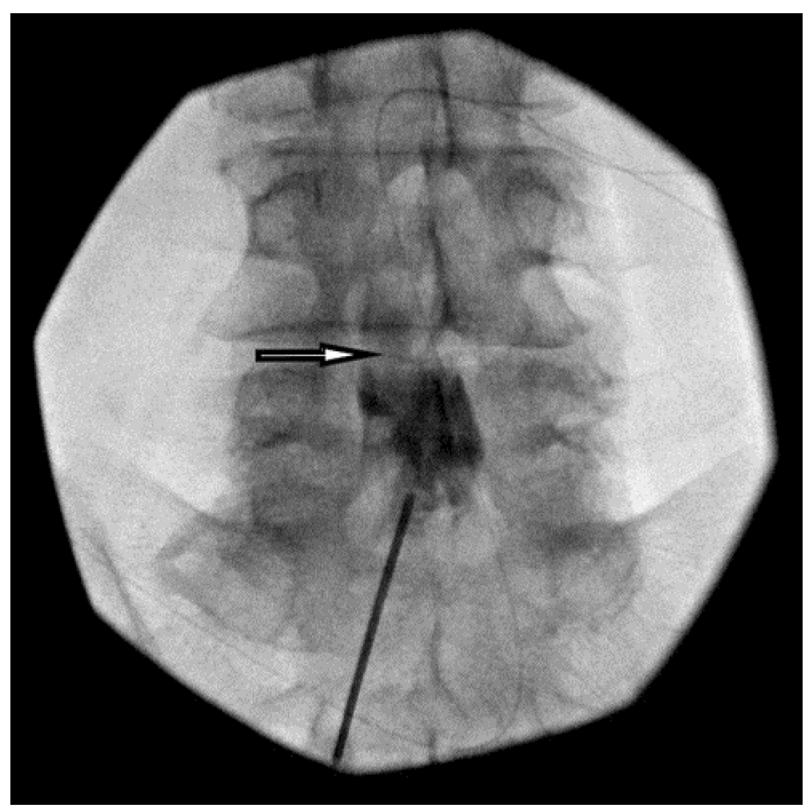

Figure 2 Fluoroscopic image of the spine during the blood patch. Arrow in the image mark the contrast spread reached the targeted epidural space at left L4-5 level.

\section{Patient 2}

A 48-year-old male with a medical history of L5-S1 decompression and fusion secondary to lumbar degenerative disc disease and L5-S1 radiculopathy. He unfortunately developed recurrent radicular pain in the $\mathrm{S} 1$ distribution for which he underwent a revision surgery of his prior instrumented interbody fusion at L5-S1. This patient was discharged home after this revision surgery. However, the medical records revealed this patient had intermittent headaches when he was discharged from the hospital. Unfortunately, his headache had become progressively worse.He was unable to sit or stand due to the severe headache when he was getting up from bed. He was re-admitted six weeks after the revision surgery for this severe positional headache. On physical examination, there were no neurological deficit or bowel and bladder dysfunction but he had nuchal rigidity. MRI of the brain revealed bilateral acute on chronic subdural hematoma with pachymeningeal enhancement. MRI of lumbar spine showed a fluid collection in the posterior paraspinal and subcutaneous soft tissue at L5 level, which was consistent with a large pseudomeningocele (Figure 3). This patient was recommended by both neurology and orthopedic surgery to have an EBP. Given the severity of his symptoms and the MRI finding of acute on chronic subdural hematoma, the EBP was carried out in a timely fashion. In order to place the blood patch close to the site of CSF leak in the L5-S1 area and to avoid going through the large pseudomeningocele located posterior to L5-S1 level of spine, we elected to enter the epidural space via caudal approach under fluoroscopic guidance and advanced an epidural catheter to target this CSF leak. During this procedure, an 18-gauge epidural needle was first placed in the sacral hiatus under fluoroscopic guidance. An epidural catheter was passed through the needle and directed in the cephalad direction until it reached S2 level. Contrast was injected and visualized the epidural space at the L5-S1 level (Figure 4). Ten milliliters of venous blood collected from the patient was injected slowly through the catheter. This patient's headache improved immediately after the procedure. Following this EBP, head computed tomography (CT) scan showed that the subdural hematoma was stable and the patient was discharged two days after the EBP. His headache completely resolved one month later. A repeat CT of head one month later showed complete resolution of bilateral subdural hemorrhages. A repeat MRI of lumbar spine four months later showed marked improvement of 


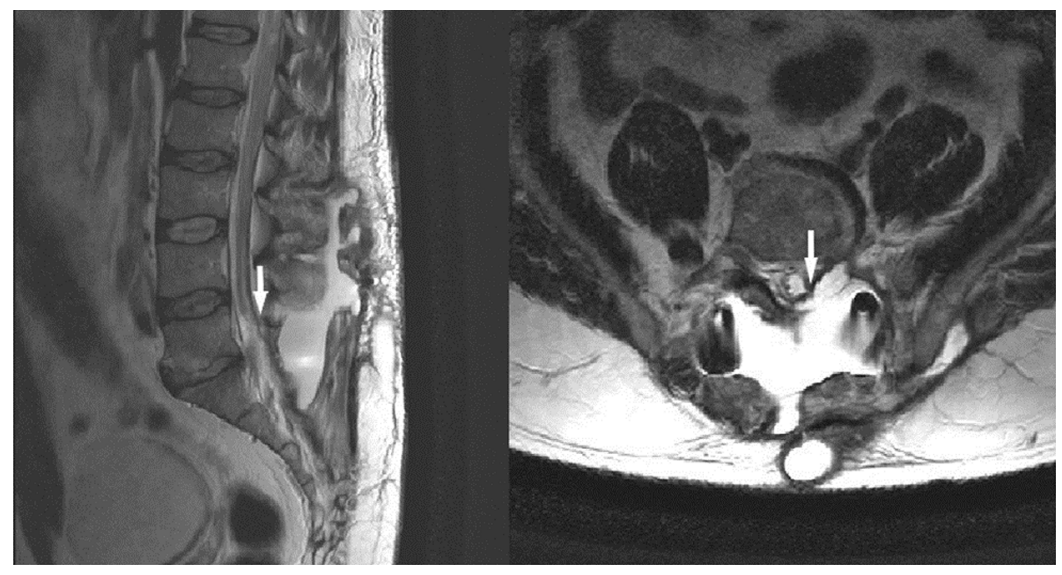

Figure $3 \mathrm{MRI}$ of the lumbar spine showed a fluid collection in the posterior paraspinal and subcutaneous soft tissue at L5 level, which was consistent with a large pseudomeningocele as marked by the arrows. Left: sagittal view, Right: axial view.

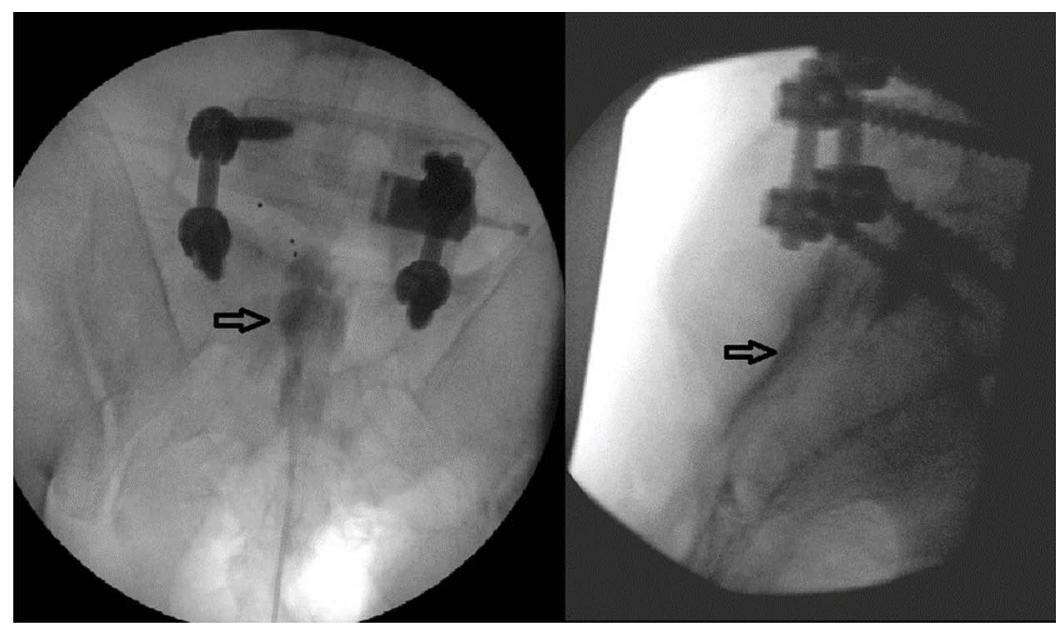

Figure 4 Fluoroscopic image of the spine during the blood patch. Arrows in the images mark the contrast spread in the epidural space. Image on the left depicts the AP view while image on the right depicts lateral view.

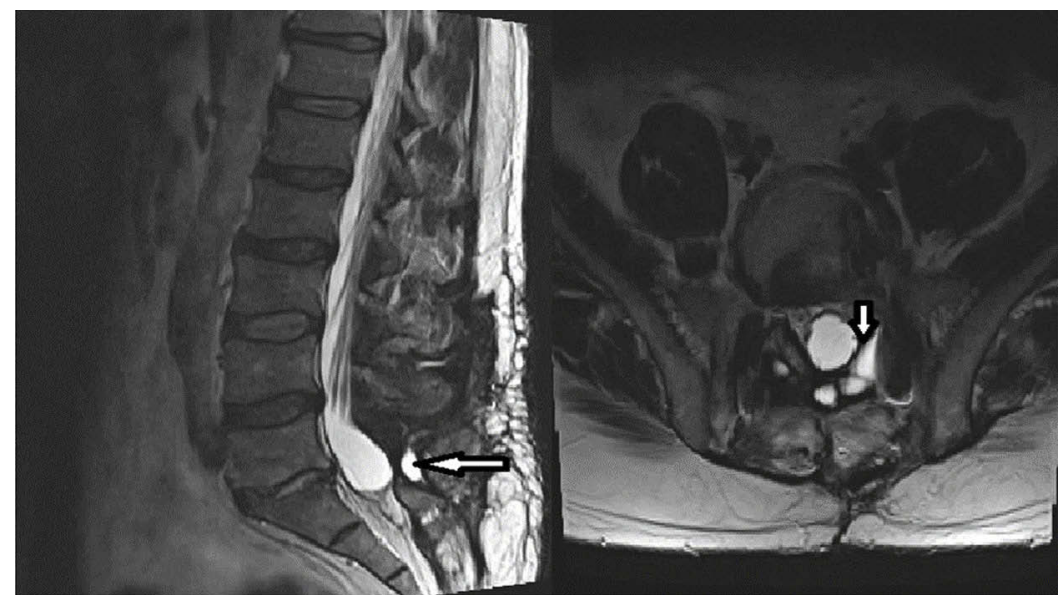

Figure 5 Repeat MRI of the lumbar spine after four months showed marked resolution of the fluid collection in the posterior paraspinal and subcutaneous soft tissue at L5 level as marked by the arrows. Left: sagittal view, Right: axial view. 
the pseudomeningocele. (Figure 5) At a four-month follow-up, this patient remained headache free.

\section{Patient 3}

A 44-year-old female who has a medical history of motor vehicle accident with cervical radiculopathy. She presented with severe positional headache seven days after a left C5-6 foraminotomy in an outside hospital. The intensity of her headache was at 10/10. She described her headache as diffused pressure-like sensation associated with neck pain, nausea, vertigo and blurry vision. This patient was unable to sit or stand due to her severe positional headache. Conservative treatments with hydration, caffeine, and oxycodone failed to provide her with any improvement. Her cervical spine MRI scan revealed an epidural fluid collection in the cervical and upper thoracic regions (Figure 6). EBPs were recommended by neurosurgery. Subsequently, this patient received two cervical EBPs one week apart. Both of those cervical EBPs were performed under fluoroscopic guidance to target the left C5-6 region, which was the level of her prior cervical foraminotomy. The EBPs were performed in the same fashion with left paramedian approach under fluoroscopic guidance. For the procedure, an $18 \mathrm{G}$ Tuohy needle was used to access the epidural space at C7-T1 interlaminar space with loss of resistance technique. This was followed by introducing an

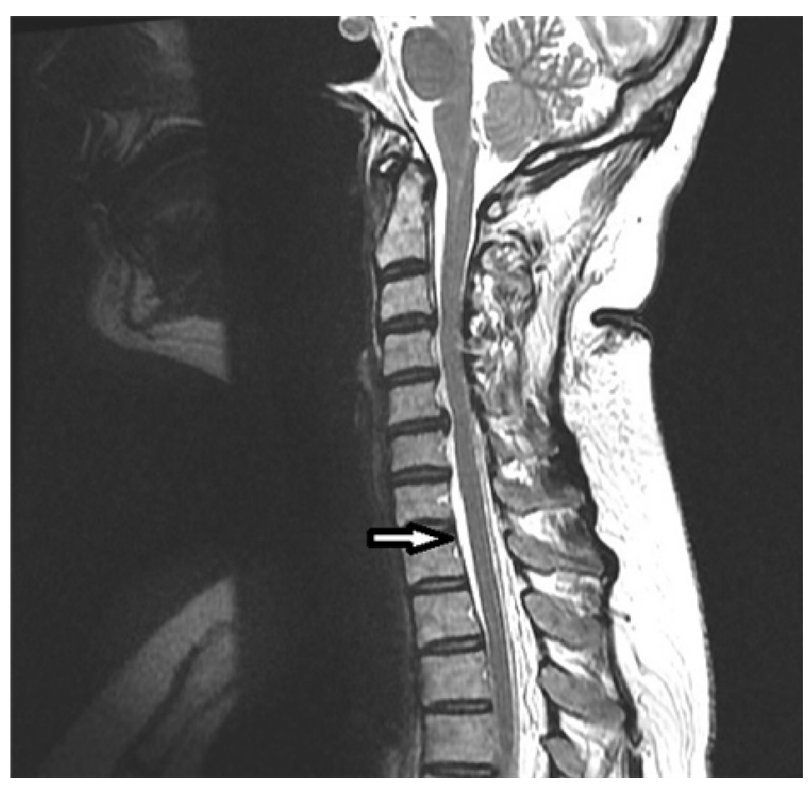

Figure 6 Cervical spine MRI sagittal view revealed epidural fluid collection in cervical and upper thoracic spine as marked by the arrow.

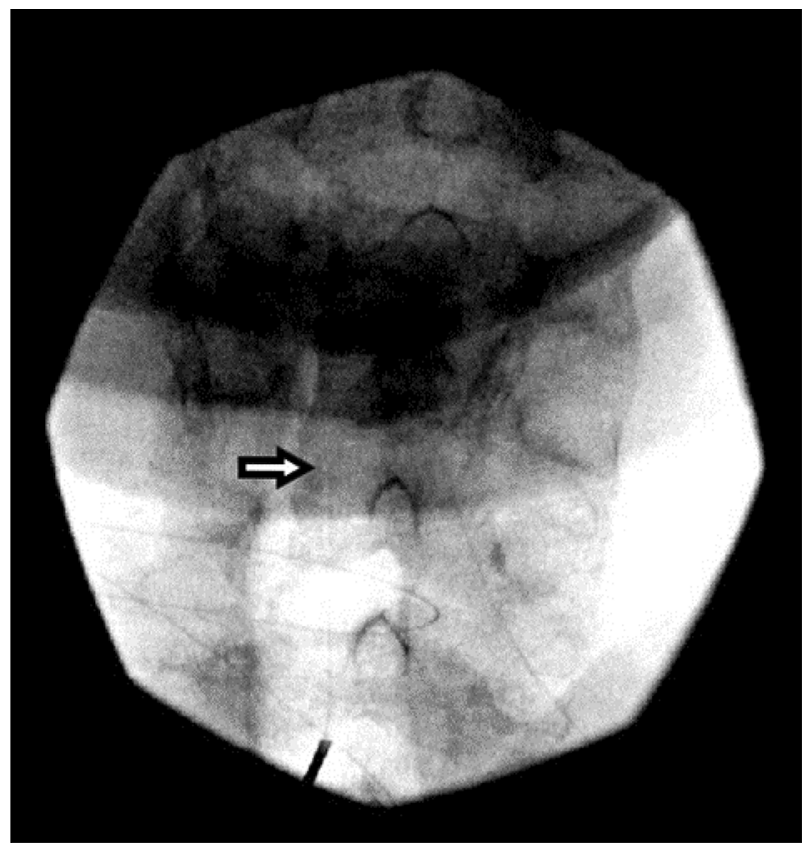

Figure 7 Fluoroscopic image of the spine during the epidural blood patch. Arrow in the image marks the site of needle entry at C7-TI interlaminar space and the tip of epidural catheter at left side $\mathrm{C} 6$ level.

epidural catheter through the needle. The catheter was then directed to left side of epidural space at C5-6 level. Approximately $0.5 \mathrm{~mL}$ of contrast was injected through the catheter to confirm epidural spread. Subsequently, $4 \mathrm{~mL}$ of autologous venous blood was injected through the catheter (Figure 7). Both EBP procedures were done under conscious sedation with no complications. However, each of the EBPs only provided her with temporary improvement for two to three days. Since this patient did not improve with further conservative treatments, she eventually underwent surgical repair of the dural leak at about four weeks after her initial foraminotomy. Fortunately, she recovered well after the surgery and her headache resolved.

\section{Patient 4}

A 55-year-old male who underwent right L4-5 and L5-S1 laminectomy was re-admitted two days after this surgery for mild headache, neck pain, and significant swelling at the lower back surgical incision site. His lumbar spine MRI revealed a large CSF collection at L4-5 level extending from the spinal canal into the laminectomy bed, paravertebral regions and subcutaneous tissues (Figure 8). He was evaluated by neurosurgery and he was recommended to have a lumbar EBP with drainage of this fluid 


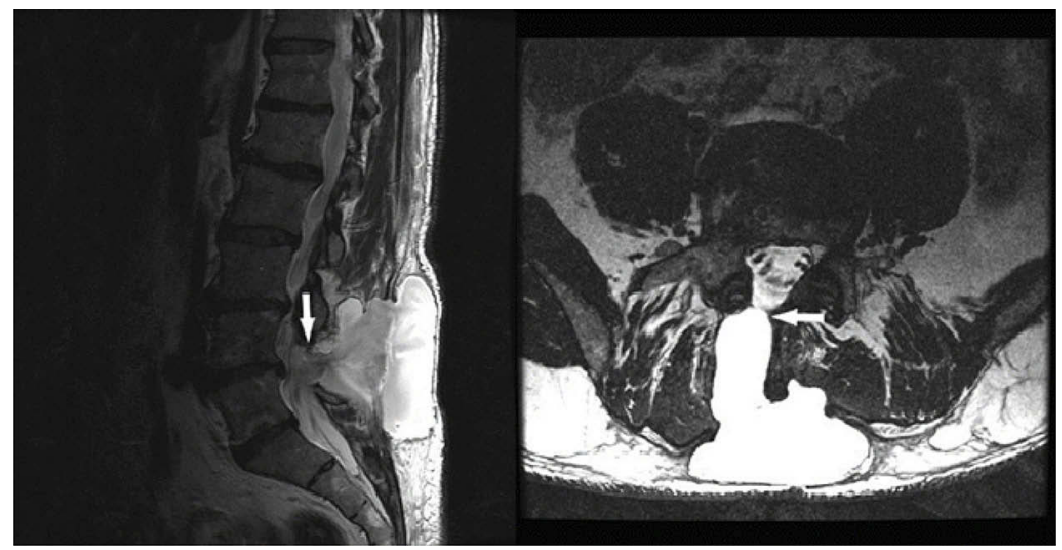

Figure $8 \mathrm{MRI}$ of the lumbar spine showed a large CSF collection at L4-5 level extending from the spinal canal into the laminectomy bed, paravertebral regions, and subcutaneous tissues. The site of CSF leak was marked by the arrow. Left: sagittal view, Right: axial view.

collection. Given the large size of CSF collection revealed by MRI, the decision was made to proceed with this intervention on an urgent basis.

This EBP was performed under fluoroscopic guidance. According to the postoperative MRI, the site of CSF leak was in the right L4-5 laminectomy area and the left side L4 and L5 lamina remained intact. In order to access the epidural space close to the site of CSF leak with loss of resistance technique, we used a left paramedian approach to target the left L5 lamina. During the procedure, the left L5 lamina was first identified by fluoroscopy, an 18-gauge epidural needle was placed on the skin and advanced toward the left L5 lamina. We were able to aspirate about $100 \mathrm{~mL}$ of the fluid collection while this needle was in the subcutaneous level. This needle was then further advanced under fluoroscopic guidance to the left side L5 lamina. After the needle reached the lamina, it was redirected superiorly and medially into the ligamentum flavum. The loss of resistance was accomplished when needle reached the midline of interlaminar space. There was no fluid return after the needle entered the epidural space. Subsequently, $2 \mathrm{~mL}$ of contrast was injected and contrast was visualized in the right side of the epidural space at L4-5 level. Fourteen milliliters of autologous blood was injected through the needle. This patient tolerated the procedure well with no apparent immediate complications. However, he reported no improvement of headache immediately after the blood patch. Unfortunately, one day after the epidural blood patch, he was found to have re-accumulation of CSF in the lower back. The patient underwent a surgical dural repair two days after the EBP. The dural repair was successful and the patient was discharged three days later.

\section{Discussion}

Incidental durotomy is a common complication following spine surgeries. ${ }^{1}$ The signs and symptoms of an incidental durotomy are caused by persistent leak of CSF into the epidural space. An unsuccessful repair or persistent leak is suspected when patients continue to have positional headaches, severe photophobia or nausea and vomiting. ${ }^{1}$ Complications of persistent CSF leaks include CSF fistula formation, poor wound healing, pseudocyst formation, nerve root compression, cranial nerve palsy, meningitis, or subdural hematoma. Appropriate and timely treatments are necessary to alleviate the symptoms and prevent complications. Conservative management is usually effective. However, when conservative management fails, patients will require additional surgeries to repair dural tears. Khan reported, in a retrospective review, that conservative management was effective and safe for the majority of these patients. However, $1.8 \%$ of the patients in this study required surgical repairs. ${ }^{3}$ Incidental dural tear is associated with significantly increased hospital cost, most likely secondary to prolonged hospital stay and a greater incidence of other complications such as hematoma and neurological injury. This increase in hospital cost is greater in cervical durotomies compared to lumbar durotomies. ${ }^{13}$ Although surgical management of incidental durotomy has been well defined in the literature, the efficacy and safety of EBP is not yet defined. ${ }^{14}$ In this case series, we demonstrated that EBP can be an effective and safe intervention for CSF leaks related to spine surgeries. EBP may also shorten the length of hospital stay by avoiding prolonged conservative management including bed rest, and its secondary medical complications including urinary tract infection and thromboembolic events. ${ }^{15}$ 
Epidural blood patch is a well-established intervention for postdural puncture headaches with long-term success rates ranging from $70 \%$ to $98 \% .{ }^{16}$ Epidural blood patch was shown to be effective for patients with postdural puncture headache related intrathecal drug delivery system. ${ }^{17}$ In addition, high volume blood patch with 40 $\mathrm{mL}$ injected into epidural space was proven to be successful in the prevention of postdural puncture headache following intrathecal catheter pump exchange. ${ }^{18}$ However, there are only a few case reports in the literature demonstrating the efficacy and safety of EBP in treatment of CSF leaks or fistula following spinal surgery procedures. ${ }^{7-11,19}$ In this case series, we demonstrated two out of three patients with lumbar CSF leaks reported improvement of symptoms following EBP. However, the cervical EBP was not successful despite two attempts. It is worth noting that CSF leaks in cervical region may be more difficult to treat. Unlike lumbar spine surgeries, incidental dural tears during anterior exposure of cervical spine canal are located in the anterior aspect of the epidural space, which is potentially more difficult to patch with our conventional interlaminar epidural injection approach designed to access the posterior epidural space. It should also be noted that the exact size of dural tear, which is unknown in our case, is another important factor that can contribute to the outcome of the EBP. Conceivably, large size tears may require surgical repair. Unfortunately, there is no imaging technology available to directly evaluate the size of dural tear. However, the MRI of the patient who failed lumbar EBP revealed a very large CSF collection (Figure 8), which is suggestive of a large tear. This patient eventually required surgical repair. Other factors that may potentially affect the outcome of EBP are the amount of blood injected and BMI. For our EBPs in the lumbar region, $10 \mathrm{~mL}$ to 14 $\mathrm{mL}$ of autologous blood was injected, which is consistent with current practice. ${ }^{20}$ We chose to use a smaller amount of blood $(4 \mathrm{~mL})$ for the cervical patch to minimize the serious risk of spinal cord compression. Regarding BMI, it is speculated that obese people may have increased intraabdominal and epidural space pressures, which can potentially decrease the severity of headache and result in better outcome. ${ }^{21}$ However, it is not feasible to analyze the effect of BMI in this series with only four cases.

Recent studies indicated that targeted EBPs may potentially improve the outcome and reduce the complications. ${ }^{22-25}$ In this case series, we attempted to target the dural leaks with fluoroscopic guidance by placing the needle close to the leakage sites or by using an epidural catheter to target the sites of the CSF leak when direct approach was contraindicated. The use of epidural catheters under fluoroscopic guidance is not a novel technique. This technique has been reported in this patient population. Kwon et al reported a case of 39-year old female presenting with a spontaneous CSF leak treated with a targeted EBP by placing an epidural catheter in the cervical spine. ${ }^{12}$ In our cases, we used an 18 gauge epidural needle to access the epidural space under fluoroscopic guidance. This was followed by advancing an epidural catheter into the needle and directing it to the site of CSF leak. Contrast was used to confirm the appropriate placement of the catheter. Sterilely collected autologous blood was then injected through the catheters. This technique is particularly useful for the postsurgical patient population in which the lack of intact ligamentum flavum renders our traditional loss of resistance technique accessing epidural space impossible. In fact, in the two cases we chose to use epidural catheters because the patients had posterior spinal surgeries, which prevented us from using our traditional loss of resistance technique. In both cases, we accessed the epidural space from the levels below, and successfully advanced the epidural catheter to the targeted areas.

In this case series, one patient developed acute orchronic subdural hematoma due to prolonged intracranial hypotension and subsequent intracranial bleeding. This patient responded well to EBP. He was found to have complete resolution of subdural hematoma four months after the EBP. Intracranial hemorrhage is a rare but serious complication of CSF leak. ${ }^{26,27}$ The hypothesized mechanisms for intracranial hemorrhage following spine surgery are rupture of intracranial blood vessel due to increased transluminal venous pressure secondary to intracranial hypotension and stretching and possibly tearing of superior vermian veins with downward displacement of the cerebellum. ${ }^{20}$ Therefore, in our clinical practice, timely intervention to prevent severe intracranial hypotension should be carried out to reduce the incidence of this serious complication.

Previous publications related to the use of EBP for treatment of incidental durotomies following spine surgery are mainly case reports. In this case series, we reported our experience that two out of the four cases responded to EBPs. Clearly, larger scale studies are required to determine the efficacy of EBP for CSF leaks related to spine surgeries. To the best of our knowledge, this is the largest case series reportingthe efficacy of EBP in the treatment of incidental durotomies. 
In conclusion, this case series demonstrated that targeted EBP can be an effective treatment for CSF leak from incidental durotomies. However, some patients may eventually require surgical dural repair. Larger scale studies are required to assess the success rate of EBP in the treatment of symptomatic incidental durotomies.

\section{Acknowledgments}

The abstract of this paper was presented at the American Academy of Pain Medicine Annual meeting 2018 as a poster presentation with interim findings. The poster's abstract was published in "Poster Abstracts" in Pain Medicine, April 2018; 19(4). This publication was made possible, in part, by support from the Thomas Jefferson University and the Philadelphia University Open Access Fund.

\section{Disclosure}

The authors report no conflicts of interest in this work.

\section{References}

1. Than KD, Wang AC, Etame AB, La Marca F, Park P. Postoperative management of incidental durotomy in minimally invasive lumbar spinal surgery. Minim Invasive Neurosurg. 2008;51(5):263-266.

2. Herren C, Sobottke R, Mannion AF, et al. Incidental durotomy in decompression for lumbar spinal stenosis: incidence, risk factors and effect on outcomes in the spine tango registry. Eur Spine J. 2017;26 (10):2483-2495.

3. Khan MH, Rihn J, Steele G, et al. Postoperative management protocol for incidental dural tears during degenerative lumbar spine surgery: a review of 3,183 consecutive degenerative lumbar cases. Spine (Phila Pa 1976). 2006;31(22):2609-2613.

4. Cammisa FP Jr, Girardi FP, Sangani PK, Parvataneni HK, Cadag S, Sandhu HS. Incidental durotomy in spine surgery. Spine (Phila Pa 1976). 2000;25(20):2663-2667.

5. Turnbull DK, Shepherd DB. Post-dural puncture headache: pathogenesis, prevention and treatment. Br J Anaesth. 2003;91(5):718-729.

6. Taivainen T, Pitkanen M, Tuominen M, Rosenberg PH. Efficacy of epidural blood patch for postdural puncture headache. Acta Anaesthesiol Scand. 1993;37(7):702-705.

7. Clendenen SR, Pirris S, Robards CB, Leone B, Nottmeier EW. Symptomatic postlaminectomy cerebrospinal fluid leak treated with 4-dimensional ultrasound-guided epidural blood patch. J Neurosurg Anesthesiol. 2012;24(3):222-225.

8. Fridley JS, Jea A, Glover CD, Nguyen KP. Symptomatic postsurgical cerebrospinal fluid leak treated by aspiration and epidural blood patch under ultrasound guidance in 2 adolescents. $J$ Neurosurg Pediatr. 2013;11(1):87-90.

9. Gilly GM Jr, Thomas M. Successful epidural blood patch after dural tear. A A Case Rep. 2014;2(11):133-134.
10. Huch K, Kunz U, Kluger P, Puhl W. Epidural blood patch under fluoroscopic control: non-surgical treatment of lumbar cerebrospinal fluid fistula following implantation of an intrathecal pump system. Spinal Cord. 1999;37(9):648-652.

11. Maycock NF, van Essen J, Pfitzner J. Post-laminectomy cerebrospinal fluid fistula treated with epidural blood patch. Spine (Phila Pa 1976). 1994;19(19):2223-2225.

12. Kwon SY, Kim YS, Han SM. Spontaneous C1-2 cerebrospinal fluid leak treated with a targeted cervical epidural blood patch using a cervical epidural Racz catheter. Pain Physician. 2014;17(3):E381-384.

13. Nandyala SV, Elboghdady IM, Marquez-Lara A, Noureldin MN, Sankaranarayanan S, Singh K. Cost analysis of incidental durotomy in spine surgery. Spine (Phila Pa 1976). 2014;39(17):E1042-1051.

14. Dafford EE, Anderson PA. Comparison of dural repair techniques. Spine J. 2015;15(5):1099-1105.

15. Radcliff KE, Sidhu GD, Kepler CK, et al. Complications of flat bed rest after incidental durotomy. Clin Spine Surg. 2016;29(7):281-284.

16. Abouleish E, Vega S, Blendinger I, Tio TO. Long-term follow-up of epidural blood patch. Anesth Analg. 1975;54(4):459-463.

17. Bendel MA, Moeschler SM, Qu W, et al. Treatment of refractory postdural puncture headache after intrathecal drug delivery system implantation with epidural blood patch procedures: a 20 -year experience. Pain Res Treat. 2016;2016:2134959.

18. Abdulla S, Vielhaber S, Heinze HJ, Abdulla W. A new approach using high volume blood patch for prevention of post-dural puncture headache following intrathecal catheter pump exchange. Int J Crit Illn Inj Sci. 2015;5(2):93-98.

19. Kim J, Lee S, Ko Y, Lee W. Treatment with epidural blood patch for iatrogenic intracranial hypotension after spine surgery. $J$ Korean Neurosurg Soc. 2012;52(3):254-256.

20. Sjovall S, Kokki M, Turunen E, Laisalmi M, Alahuhta S, Kokki H. Postdural puncture headache and epidural blood patch use in elderly patients. J Clin Anesth. 2015;27(7):574-578.

21. Kokki M, Sjovall S, Keinanen M, Kokki H. The influence of timing on the effectiveness of epidural blood patches in parturients. Int $J$ Obstet Anesth. 2013;22(4):303-309.

22. Takai K, Taniguchi M. Targeted epidural blood patch under O-armguided stereotactic navigation in patients with intracranial hypotension associated with a spinal cerebrospinal fluid leak and ventral dural defect. World Neurosurg. 2017;107:351-357. Located at:.

23. Tontisirin N, Benjhawaleemas P, Nimmaanrat S, et al. Cervical foraminal epidural blood patch for the targeted treatment of refractory cerebrospinal fluid leakage from a dural sleeve. Reg Anesth Pain Med. 2018;43(2):205-210.

24. Yoshida H, Takai K, Taniguchi M. Leakage detection on CT myelography for targeted epidural blood patch in spontaneous cerebrospinal fluid leaks: calcified or ossified spinal lesions ventral to the thecal sac. J Neurosurg Spine. 2014;21(3):432-441.

25. Leung W, Shaffer CD, Reed LK, et al. Drosophila muller $f$ elements maintain a distinct set of genomic properties over 40 million years of evolution. G3 (Bethesda). 2015;5(5):719-740.

26. Khalatbari MR, Khalatbari I, Moharamzad Y. Intracranial hemorrhage following lumbar spine surgery. Eur Spine J. 2012;21 (10):2091-2096.

27. Farag E, Abdou A, Riad I, Borsellino SR, Schubert A. Cerebellar hemorrhage caused by cerebrospinal fluid leak after spine surgery. Anesth Analg. 2005;100(2):545-546. 


\section{Publish your work in this journal}

The Journal of Pain Research is an international, peer reviewed, open access, online journal that welcomes laboratory and clinical findings in the fields of pain research and the prevention and management of pain Original research, reviews, symposium reports, hypothesis formation and commentaries are all considered for publication. The manuscript management system is completely online and includes a very quick and fair peer-review system, which is all easy to use. Visit http:// www.dovepress.com/testimonials.php to read real quotes from published authors.

Submit your manuscript here: https://www.dovepress.com/journal-of-pain-research-journal 